\title{
Articles
}

\section{An NMR Study on Complexation of Cesium Ion by p-tert-Butylcalix[6]arene Ethyl Ester}

\author{
Kee-Choo Chung, Hỵu Namgoong, ${ }^{\dagger}$ and Jo Woong Lee \\ School of Chemistry and Molecular Engineering, College of Natural Sciences. Seoul National Universitv Seoul 151-742, Korea \\ E\&A Center, Kolon Central Research Park, Yongin 477-797. Korea \\ Received Februarv 6. 2004
}

\begin{abstract}
Complexation of cesium ion by $p$-tert-butylcalix[6]arene ethyl ester was studied by NMR spectroscopy in nonpolar $\mathrm{CDCl}_{3}$ and polar acetone- $d_{6}$ and the results were compared with each other. Analy sis of temperature dependent ${ }^{1} \mathrm{H}$ spectra and titration curves reveals that both solvents result in a $1: 1$ cone-form complex with nonpolar $\mathrm{CDCl}_{3}$ yielding a more tightly bound one than acetone- $d_{6}$. Unexpectedly, at very low tenperature, we have found that two pheny 1 ring proton peaks of equal intensity appear both in $\mathrm{CDCl}_{2}$ and in acetone- $d_{6}$ solution which gradually collapse and eventually coalesce into a single line as temperature is raised. This observation could be interpreted in terms of the chemical exchange through direct and/or indirect interconversion between two equivalent conformations possible the complex in both solvents over the temperature range observed. And broadening of ${ }^{133} \mathrm{Cs}(I=7 / 2)$ numr line with increasing temperature has also been observed, indicating the exchange of ${ }^{139} \mathrm{Cs}$ ion between the complex and the solvent. From numerical fitting of lineshape changes for one-dimensional ${ }^{1} \mathrm{H}$ and ${ }^{133} \mathrm{Cs}$ spectra. the exchange rate constants and other relevant parameters for this conformational interconversion and the complex-solvent exchange were deduced.
\end{abstract}

Key Words : NMR. Calix[6]arene. Cesium. Chemical exchange

\section{Introduction}

Calixarenes have attracted widespread attention because of their ability to interact with various metal ions. ${ }^{1}$ For example. calixarene-based metalloreceptors are increasingly' employed usefully in various applications such as analytical luminescent sensors ${ }^{2}$ and highly luminescent lanthanidecontaining probes ${ }^{\hat{3}}$ as well as metal extraction and separation reagents. ${ }^{+}$To understand the structure of metal-calixarene complex in terms of the interaction between metal ion and host calixarene can also be important because it provides a guideline for use of a conformational template of the specific calixarene skeleton ${ }^{5}$ for synthesis of polymeric sensory materials ${ }^{6}$ as well as new calixarene derivatives. ${ }^{7,8}$ In addition to the topic of structure of metal-calixarene complexes the location of metal binding site has also interested several researchers who have published some reports on this subject ${ }^{\text {sti }}$ Calixarene derivatives usually show ambidentate character. binding some metal ions in the calixarene basket formed by surrounding phenyl rings while others at the lower rim oxy'gen sites. J. M. Harrowfield et al revealed by $\mathrm{X}$-ray crystallography that the binding site of cesium ion with calix[4]arene in $\mathrm{CH}_{3} \mathrm{CN}$ solution is located within the inclusive calixarene basket instead of being around the oxygen atoms. While Shinkai et al. demonstrated that sodium ion. on the contrary. binds at the oxygen sites in THF

Corresponding Author: liw329 âanananet net solution. ${ }^{115}$ Several factors such as metal ion size. solvent polarity etc. may account partly or fully. for these differences but the exact reason is not fully understood yet.

Recently, among alkali metals. cesium has attracted particular attentions because it is a major important component of nuclear wastes which may pollute water and soil. ${ }^{11,12}$ This has stimulated the studies on calixarenes which can act as separation and extraction reagents for this detrimental metal. Such studies included the syinthesis of calix[4]arene based benzocrowns as a cesium selective fluorescent probe. ${ }^{13}$ molecular dynamics study about cesium binding ability of calix[4]arene based macromolecules. ${ }^{14}$ etc. Also there have been numerous reports on the structure of $\mathrm{Cs}^{-}$complexes with calix[4]arene derivatives. B. A. Murray et al. reported the synthesis of calix[4]arene derivatives of cone conformation which retain the same conformation even after complexing with cesium. ${ }^{15}$

In contrast to the case of calix[4]arenes. not much has been reported on the complexation of cesium ion by their hexamer counterparts. which may be due to the fact that the latter have larger and more flexible cavities than their tetramer counterparts. thus being inherently more complex both structurally and functionally. despite the advantage that more functional groups can easily be substituted into them. Such lack of information regarding calix[6]arenes has prompted us to take up the investigation we report in this paper. For the study concerning the details of complexation of cesium ion by calix[6]arenes in solution phase. liquid 
NMR spectroscopy provides a suitable tool since sharp NMR resonance lines are usually observed for ${ }^{133} \mathrm{Cs}(I=$ $7 / 2$ ), in contrast to other alkali metal ions, due to its exceptionally sntall quadrupole moment $\left(Q=-3 \times 10^{-3}\right.$ bann $\left.^{5}\right){ }^{16}$ In our present work complexation of cesium ion by p-tertbutylcalix[6]arene ethyl ester has been studied by observing the changes of chemical shift and lineshape of both ${ }^{133} \mathrm{C}$ and ${ }^{1} \mathrm{H}$ unir lines in two different solvents. polar acetone- $d_{6}$ and nonpolar $\mathrm{CDCl}_{3}$ at various temperatures. The unir chemical shifts of ${ }^{133} \mathrm{Cs}$ in $\mathrm{Cs}^{-}$-calix[6] arene derivatives complexes are found to depend strongly on the solvent property and the more polar solvent leads to the nnir lines observed at the lower fields. Calixarenes tend to dissolve better in non-polar solvents than in polar ones. while most metal salts used as guest are ionic and prefer polar solvents. Metal-calix complexes are, however, usually soluble in both polar and nonpolar solvents, which made our observations possible in both polar acetone- $d_{6}$ and nonpolar $\mathrm{CDCl}_{3}$ solutions. In consideration of the solubility of cesium picrate and calix[6]arene ethyl ester in various solvents, we have chosen just the two solvents, $\mathrm{CDCl}_{3}$ and acetone- $d_{6}$, for comparison.

\section{Theory of Chemical Exchange between two Uncoupled Sites}

In this section we briefly outline the theory of chemical exchange between two nonequivalent uncoupled sites. although it is very well established and its description can be found in standard NMR textbooks. ${ }^{17}$ because we frequently invoke it into our discussion for quantitative results obtained in the present paper.

Consider a system hopping between two different states $A$ and $B$.

$$
\text { State } A-\frac{k_{a b}}{k_{b a}}-\text { State } B
$$

where $k_{a b}$ and $k_{b u}$ are. respectively, the forward and reverse exchange rate from $A$ to $B$ and $B$ to $A$; that is, the inverse of lifetime at the two states $A$ and $B$ shown in $\mathrm{Eq}$. (I). The complex NMR spectrum is determined under slow passage condition by the following equations:

$$
\begin{aligned}
& d M_{. i}^{+} / d t=i \gamma B_{1} M_{. i z}+i\left(\omega_{. i}-\omega\right) M_{. i}^{+}-M_{. j} / T_{2 . i} \\
& -k_{a, b} M_{A}^{+}+k_{b a} M_{B}^{-} \\
& d M_{B}^{+} / d t=i \gamma B_{1} M_{B=}+i\left(\omega_{B}-\omega\right) M_{B}^{+}-M_{B} / T_{2 B} \\
& \text { - } k_{b, a} M_{B}^{+}+k_{a r k} M_{A}^{-}
\end{aligned}
$$

where $M_{A}^{+}$and $M_{B}^{+}$are. respectively, the transverse complex magnetization $M^{+} \equiv M_{x}+i M_{v}$ developed at the state $A$ and the state $B$ while $M_{A z}$ and $M_{B z}$ are the corresponding $z-$ components of induced magnetization. And $\omega_{A}$ and $\omega_{B}$ denote, respectively, the Larmor frequency of the given spin at the two sates $A$ and $B$ and $T_{24}$ and $T_{2 B}$ are. respectively, the corresponding spin-spin relaxation time. Also $\gamma$ and $B_{1}$ are. respectively, the magnetogyric ratio of the given spin and the strength of irradiating $r f$ field.

If steady state is reached. one may let $d M_{.1}^{+} / d t=$ $d \overline{M_{B}} / d t=0$ to have

$$
\begin{aligned}
& {\left[i\left(\omega_{-4}-\omega\right)-1 / T_{2.1}-k_{a b}\right] M_{-4}+k_{b, r} M_{B}^{+}=-i \gamma B_{1} M_{. i=}^{\prime}} \\
& k_{a r c t} M_{A}+\left[i\left(\omega_{B}-\omega\right)-1 / T_{2 B}-k_{b_{A}}\right] M_{B}^{+}=-i \gamma B_{1} M_{B z}^{\prime}
\end{aligned}
$$

where $M_{A z}$ and $M_{B=}^{\prime}$ are. respectively the equilibrium value of $M_{i=}$ and $M_{B}$ :

After sloving Eq. (3) with respect to $M_{A}$ and $M_{B}^{+}$we can obtain the lineshape function from imaginary part of $\overline{M^{-}} \equiv \overline{M^{+}}+M_{B}^{+}$and the result may be expressed as follows:

$$
\operatorname{Sin}(M)=\gamma B_{1} M_{(1} \frac{P\left[1+\tau\left(p_{B} / T_{2 . A}+p_{A .} / T_{2 B}\right)\right]+Q R}{P^{2}+Q^{2}}
$$

where $p_{4}$ and $p_{B}$ are. respectively. the probability of finding the given nucleus at the state $A$ and the state $B$. and

$$
\begin{aligned}
P= & \tau\left[\frac{1}{T_{2 . A} T_{2 B}}-(\Delta \omega)^{2}+\frac{1}{4}(\delta \omega)^{2}\right]+\frac{p_{-A}}{T_{2 A}}+\frac{p_{B}}{T_{2 B}} . \\
Q= & \tau\left[\Delta \omega-\frac{1}{2} \delta \omega\left(p_{A A}-p_{B}\right)\right] . \\
R= & \Delta \omega\left[1+\tau\left(\frac{1}{T_{2 . A}}+\frac{1}{T_{2 B}}\right)\right]+\frac{1}{2} \delta \omega \tau\left(\frac{1}{T_{\triangle B}}-\frac{1}{T_{2 . A}}\right) \\
& +\frac{1}{2} \delta \omega\left(p_{A A}-p_{B}\right)
\end{aligned}
$$

with

$$
\begin{gathered}
\tau=\frac{p_{A i}}{k_{b a}}=\frac{p_{B}}{k_{c i b}} . \Delta \omega=\frac{1}{2}\left(\omega_{A}+\omega_{B}\right)-\omega . \delta \omega=\left(\omega_{A}-\omega_{B}\right) . \\
M_{0}=M_{A z}^{\prime}+M_{B z}^{\prime} . M_{A=}^{\prime}=p_{A} M_{(! .} \text {and } M_{B=}^{\prime}=p_{B} M_{0} .
\end{gathered}
$$

By making use of Eq. (4) we can evaluate the lineshape for the exchanging system for a given set of the parameters involved. Or conversely. by least squares fitting of Eq. (4) with observed data through successive adjustment of the parameters involved we can find an adequate set of these parameters that produces the best fitting. To help this numerical fitting procedure be carried out more efficiently a mathematical routine based on the Marquadt algorithm is normally employed. as we have done in this work. The results of lineshape fitting and the thermodynamical parameters thereby deduced will be discussed in a later section.

\section{NMR Titration Curves}

The untr titration experiments provide further insight into this problem in which the change of the chemical shift of a proton line is monitored as one gradually increases the concentration ratio of guest $t s$. host and the resultant titration curve is graphically fitted with that predicted on the basis of an assumed model of chemical exchange. If we assume the chemical exchange between free and complexed host molecules. the observed chemical shift of a proton line for 


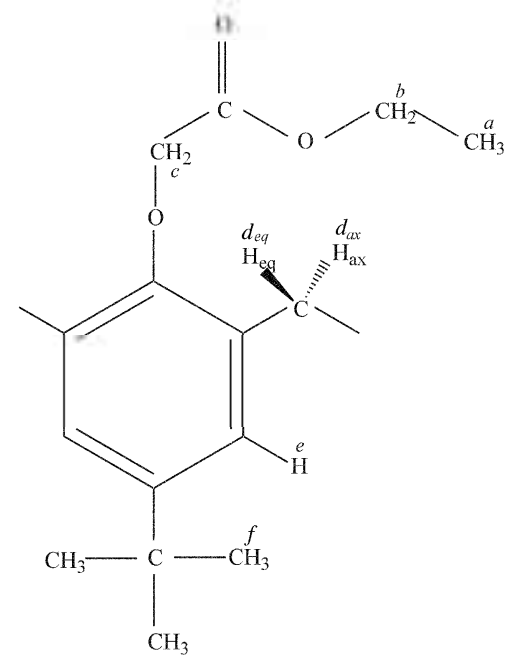

Scheme 1

this system may be expressed as

$$
\begin{aligned}
\delta_{\mathrm{ohs}}= & \frac{1}{2}\left[\left(1-\rho-1 / K_{f}[\mathrm{H}]_{f}\right)+\left\{\left(1-\rho-1 / K_{f}[\mathrm{H}]_{f}\right)^{2}\right.\right. \\
& \left.\left.+4 / K_{f}[\mathrm{H}]_{f}\right\}^{1: 2}\right] \times\left(\delta_{f}-\delta_{i}\right)-\delta_{i}
\end{aligned}
$$

The symbols appearing in $\Gamma_{\mathrm{c}}$. (9) have the following meanings:

$\delta_{\text {obs }}$ : observed chemical shift of the monitored nucleus,

$\delta_{t}$ : chemical shift of the monitored nucleus in the free host,

$\delta_{c}$ : chemical shift of the monitored nucleus in the complexed host,

$[\mathrm{H}]_{i}$ : total concentration of the host.

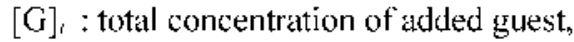

$$
\left.\rho^{-}[\mathrm{G}]_{i} / \mathrm{H}\right]_{s}
$$

with $K_{f}$ being the association constant for the host-guest complex under consideration.

We have obtained the titration curve by monitoring methyl proton $\boldsymbol{a}$ (Scheme l) for $\mathrm{CDCl}$; solution and $t$-butyl proton $f$ (Scheme 1) for acetone- $d_{0}$ solution. Each titration curve was numerically fitted with Eq. (9) to obtain the formation constant $K_{f}$. The results are shown in Figure 1(a) and (b). respectively, from which it has been concluded that the calix[6] arene ethyl ester forms a 1 : I complex with cesium ion both in $\mathrm{CDCl}_{3}$ and in acetone- $d$, The values estimated at various temperatures are also listed in lable I. The magnitude of values was found to be of the order of to over the temperature range of experiment (see lable 1), indicating that the formation of complex between the calixarene host and $\mathrm{Cs}^{-}$ion is strongly favored in both $\mathrm{CDCl}$; and acetone- $d_{6}$ solvent. The larger $K_{t}$ value for $\mathrm{CDCl}_{3}$ indicates that cesium ion is more tightly held by the calixarene host (and, thus, the resultant complex is more stable) in $\mathrm{CDCl}_{3}$ than in acetone$d_{6}$. This difference may qualitatively be understood on the basis of difference in polarity of the two solvents, considering that more polar acetone- $d_{t}$ molecules are expected to be more competitive in attracting $\mathrm{Cs}^{+}$ion away from the calixarene host than less polar $\mathrm{CDCl}_{3}$ molecules. From
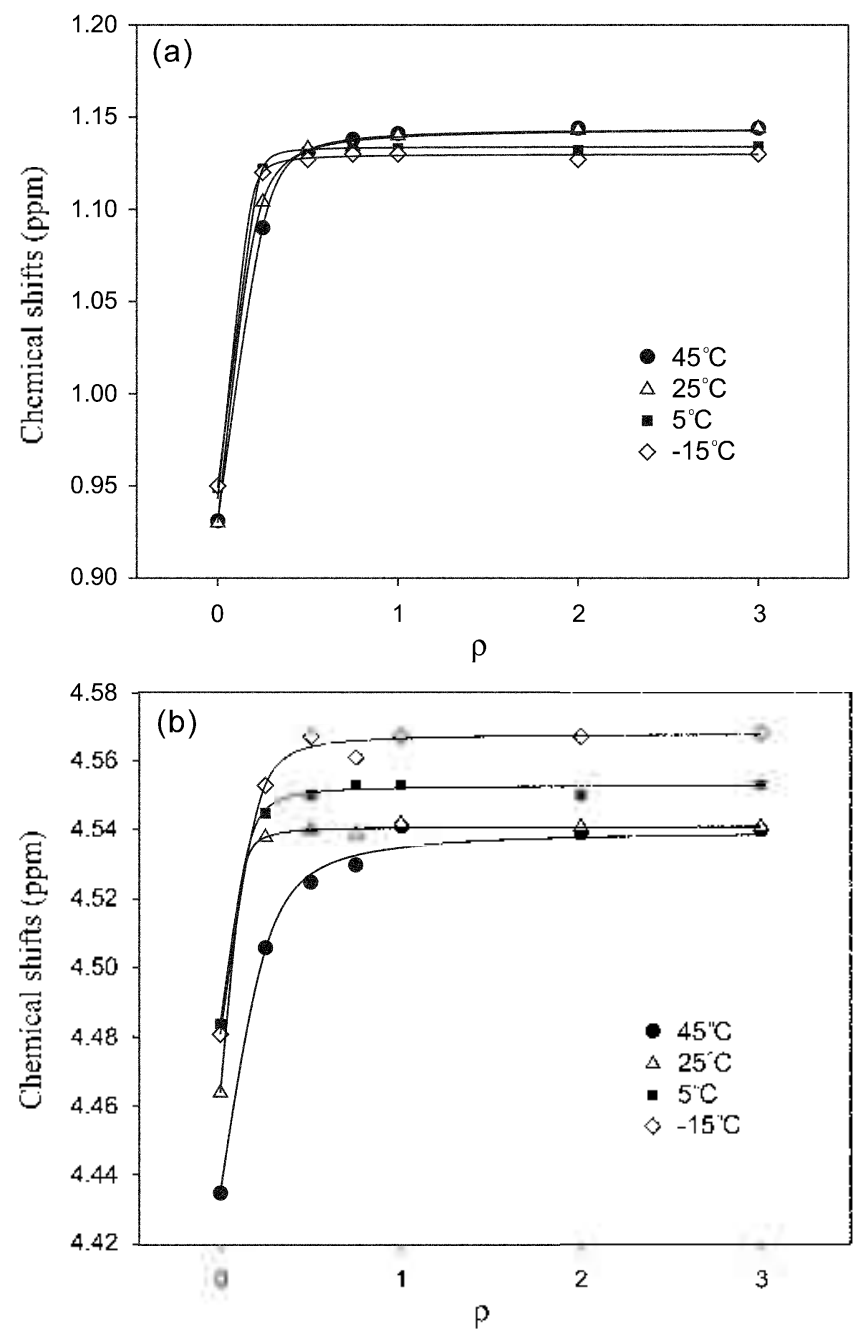

Figure 1. Plots of chmical shitts of (a) $t$-hutyl proton in acetone and (b) ether proton in $\mathrm{CDCl}_{3}$ as a lunction of guesthost ratio al several dillerent temperatures.

Table 1. Association constants and thermodyamic parameters for complexation in acetone- $d_{6}$ and $\mathrm{CDCl}_{3}$ solutions

\begin{tabular}{lccc}
\hline & & Acetone-do & CDCl $_{3}$ \\
\hline $\log K_{f}$ & $45^{\circ} \mathrm{C}$ & 3.00 & 3.83 \\
& $25^{\circ} \mathrm{C}$ & 3.30 & 3.94 \\
$5^{\circ} \mathrm{C}$ & 3.44 & 4.08 \\
$-15^{\prime \prime} \mathrm{C}$ & 3.70 & 4.20 \\
\hline$\Delta H^{\prime \prime \prime}(\mathrm{kJ} / \mathrm{mmol})$ & -17.46 & -9.62 \\
$\Delta \mathrm{S}^{\prime \prime \prime}(\mathrm{J} / \mathrm{mol} \mathrm{K})$ & 3.28 & 43.19 \\
$\Delta \mathrm{G}^{\prime \prime}{ }_{2 \%}(\mathrm{kl} / \mathrm{mol})$ & -18.44 & -22.49 \\
\hline
\end{tabular}

measured values of we could first estimate $\Delta G^{0}$, standard free energy change of complex formation, on the basis of the relation $\Delta G^{(t)}=-R T \ln K_{f}$. Plot of $\log K_{f}$ against inverse of temperature, $1 / T$, shows linear relationship for both $\mathrm{CDCl}_{3}$ and acetone- $d_{k}$ solution. from which $\Delta H^{\circ}$, standard enthalpy change of complex formation, could be estimated. ${ }^{18}$ ' lhese, then, led us to $\Delta s^{*}$, standard entropy change of complex formation at the given temperature. These are tabulated in lable 1. 


\section{Experiments and Calculations}

The $p$-tert-butylcalix[6]arene ethyl ester were prepared following the reported procedures. Both $\mathrm{CDCl}_{\$}$ and acetone$d_{0}$ (of the nmr solvent grade) were purchased from Aldrich and Sigma Chemical Co, and used without further purification. All the NMR spectra were obtained on Varian VXR$200 \mathrm{~S}$ and Jeol $\mathrm{YH} 400$ spectrometer.

For NMR titration experiment the chemical shifts of protons in host molecule were observed as a function of $\rho$ (= [guest] [host]) at four different temperatures [See Figure (a) and Figure 2(b)]. The host concentration was fixed at $0.02 \mathrm{M}$ and that of guest was varied over the range of 0 to $0.06 \mathrm{M}$.

Temperature was maintained to the accuracy of $=0.5^{\circ} \mathrm{C}$ throughout the variable temperature experiments with the aid of precalibrated variable temperature controller equipped with the NMR spectrometer. All the fitting calculations determining the parameters involved in this work, such as $K_{f}$ and the rate constants, were carried out on an IBM PC using a least-squares fitting program employing the Marquadt algorithm.

\section{Results and Discussion}

The nmr measurements for protons in $p$-tert-butylcalix[6]arene ethyl ester complexed with various alkali metal ions, $\mathrm{Li}^{+}, \mathrm{Na}^{+}, \mathrm{K}^{-}, \mathrm{Rb}^{+}, \mathrm{Cs}^{-}$, were carried out both in $\mathrm{CDCl}$; and in acetone- $d_{1}$ at several temperatures. Fxcept for acetone- $d_{0}$, the polar solvents tested were found to give only low sensitivity spectra of phenyl protons because of low solubility of calix[6]arene and metal picrates in these solvents. Hence we were forced to perform the NMR experiments in only two solvents, $\mathrm{CDCl}_{s}$ and acetone- $d_{6}$. each as representative nonpolar and polar solvent. In $\mathrm{CDCl}_{\text {; }}$, among alkali ions, only cesium was found to give a well resolved 'H NMR spectrum of the characteristic $A B$-type pattern for methylene protons $d$ (see Scheme 1) over the temperature range of $238-313 \mathrm{~K}$ as shown in Figure 2 and 3 . indicating the presence of $p$-tert-butylcalix[6]arene ethyl ester complexed with cesium ion in the form of cone conformation.' In acetone- $d_{0}$, similar $A B$ pattern for methylene protons $d$ was also observed to suggest that the Cs-calix[6]arene complex assume a cone conformation in this solvent as well. Furthermore, observed Cs NMR spectrum indicates that the complex assume an ento form since the $\mathrm{Cs}$ resonance signal in Cs-calix[6]arene complex, in contrast to the report by U.C. Meier and C. Detellier for Cs-calix[4]arene complex, ${ }^{15}$ is found at nearly 80 ppm upfield from that of the solvated $\mathrm{Cs}^{-}$ion due to the strong shielding effect caused by benzene ring current and the Cs- $\pi$ interaction inside the calixarene cavity (Figure 7).

However, the most conspicuous feature of proton NMR spectrum for our $\mathrm{Cs}^{+}$-calix[6] complex system was that two separate peaks of equal intensity could be observed for phenyl ring protons at low temperatures in both acetone- $d_{6}$ and $\mathrm{CDCl}_{3}$, as shown in Figures 2 and 3 . ' ' the authors were at
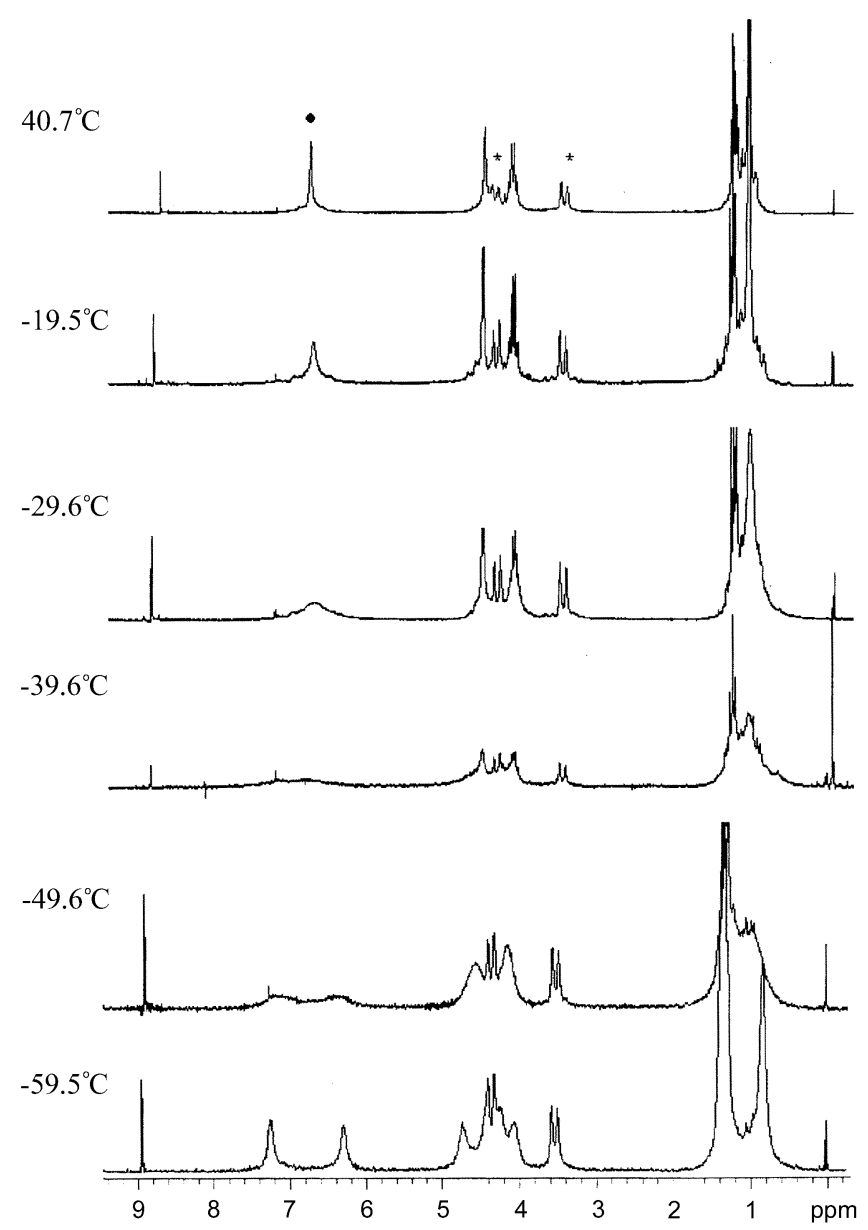

Figure 2. Proton spectrat taken at various temperatures in $\mathrm{ClOC} \mathrm{l}_{3}$ solution. Methylene proton $d$ is marked by * and phenel ring proton $e$ by $\bullet$.

first baffled by this finding because no previous encounter with such observation had ever been known or reported. One may easily be tempted to interpret these two peaks as arising from phenyl ring protons, respectively, in free calixarene and complexed one. However, this possibility could immediately be ruled out because the spectral feature did not change even in the presence of excessive $\mathrm{Cs}^{+}$concentration (See Figure 4). As reported in this work, the association constant for this system is fairly large and, therefore, in the presence of excess guest the concentration of free calixarene must be very low. Furthermore, when excess host was added, a separate peak corresponding to free calixarene was found to appear between these two peaks (see rigure 5). Therefore, it could be concluded that these two proton peaks originate from two different kinds of phenyl ring protons in the $\mathrm{Cs}^{-}$calix complex itself. In order to gain further insight into the nature of these proton peaks we also observed the lineshape change of the two phenyl ring proton peaks as a function of temperature, which showed a typical coalescence pattern of absorption lines for chemical exchange between two uncoupled sites of equal population (Figures 2 and 3). This suggests that the complex itself interconverts between two equivalent forms in which six phenyl rings are tilted alternately toward and away from the calixaene cavity as 

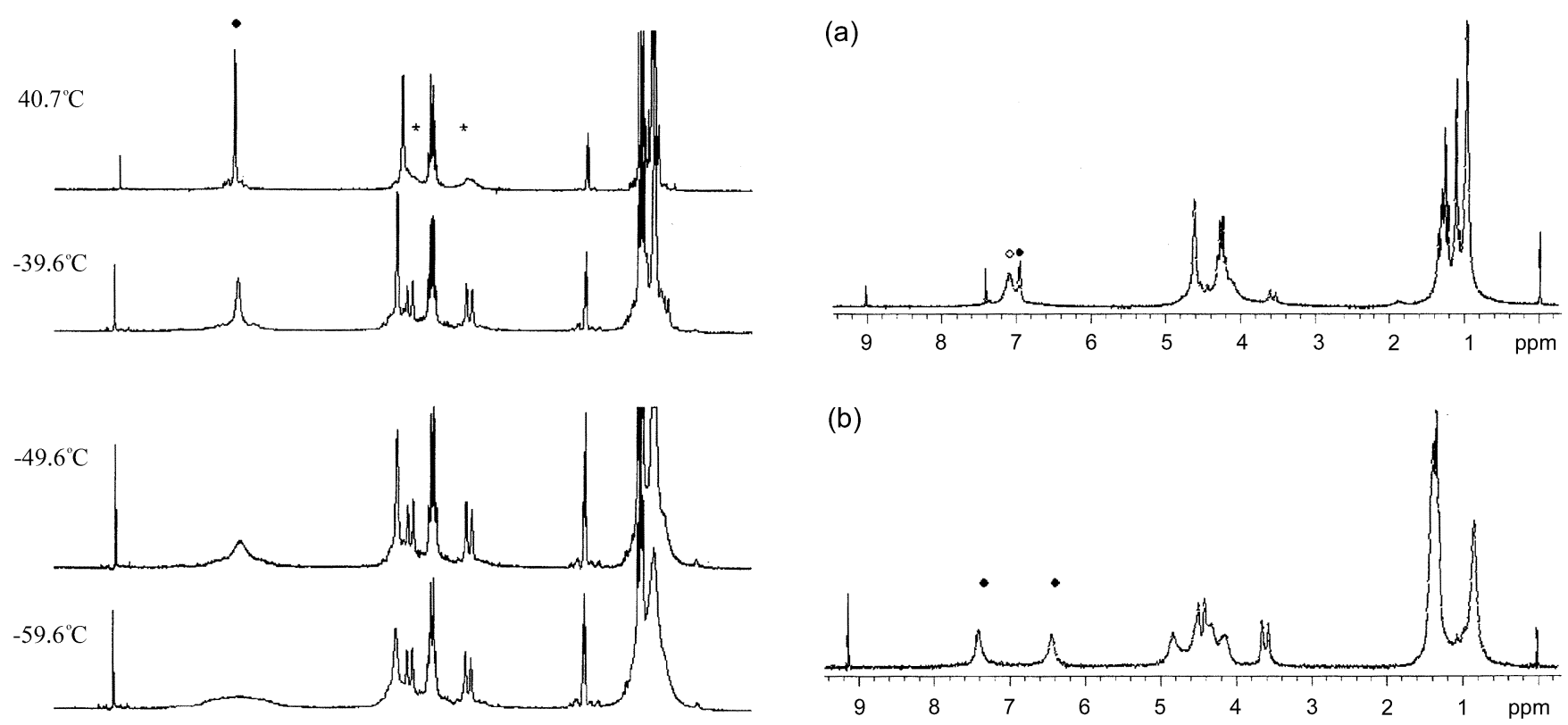

(b)

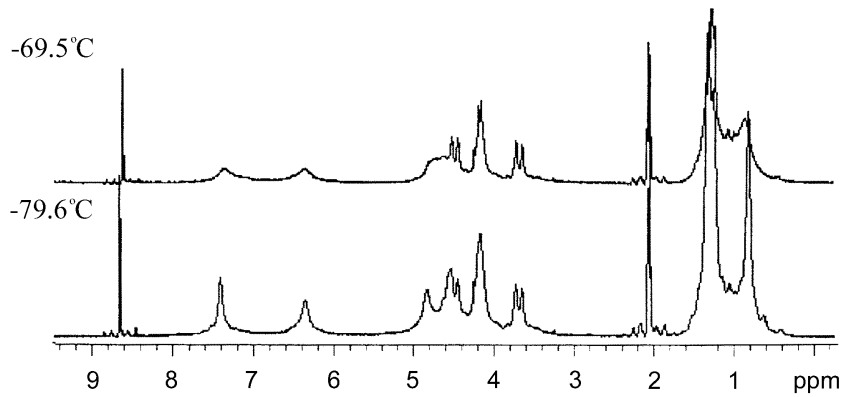

Figure 3. Proton spectrataken at various temperatures in acetoneto solution. Methylene proton $d$ is marked by * and phenyl ring proton $e$ is *.

(a)
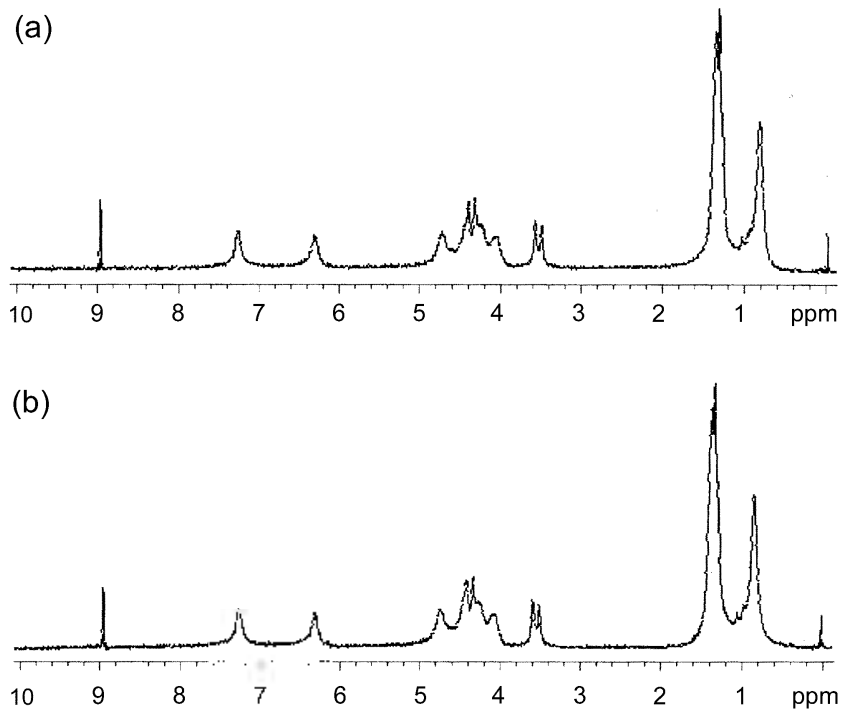

Figure 4. Proton spectra taken at the mixing ratio of (a) Calix $|6|$ : $\mathrm{Cs}=1: 1$ and (b) Calix [6] $: \mathrm{Cs}=1: 2$ at $-60^{\circ} \mathrm{C}$ in $\mathrm{CDC} \mathrm{I}_{\text {; solution. }}$

shown in Scheme 2. This structure looks somewhat similar to 1,3,5-alternate form of free calixarene, but unlike the latter it has a $C_{3}$ symmetry element but no inversion center;

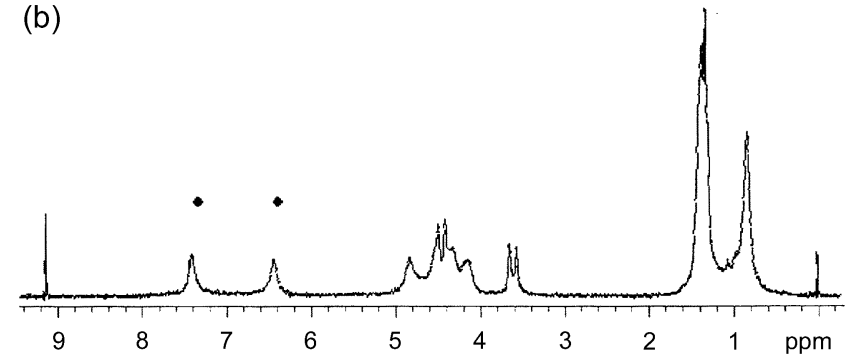

Figure 5. Proton spectra taken at the mixing ratio of (a) Calix|6l: $\mathrm{Cs}=4: 1$ at $25^{\circ} \mathrm{C}$ and (b) $\mathrm{Calix}[6]: \mathrm{Cs}=1: 1$ at $-60^{\circ} \mathrm{C}$, both in CDCl. $]_{3}$. Pheny $]$ ring proton of complesed calixarene is marked by $\bullet$ and those of liee calixarene by 2.

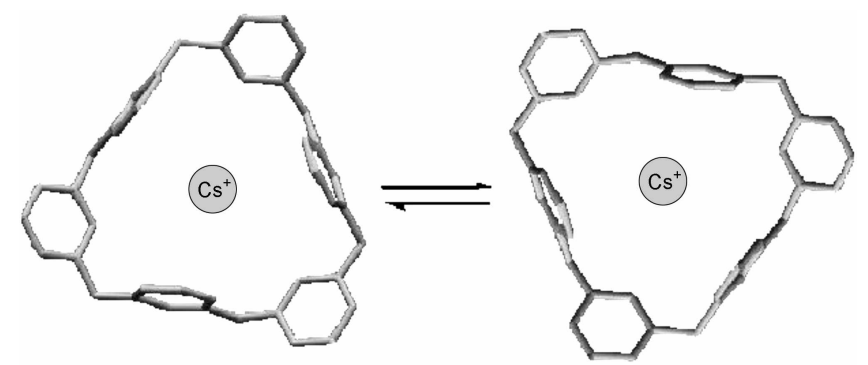

Scheme 2

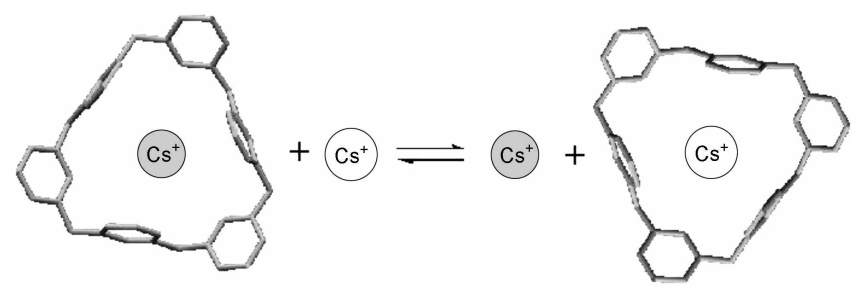

Scheme 3

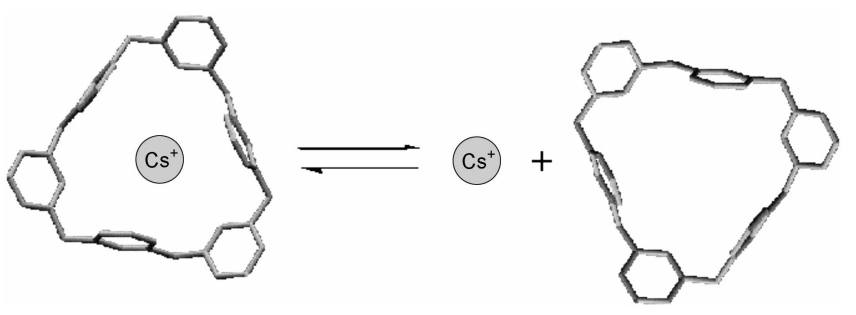

Scheme 4

that is, it has no $S_{i}$ symmetry element. In accordance with this the $A B$ pattern of metyl protons $d$ could also be seen to collapse as the complex undergoes interconversion (Figure 
(a)

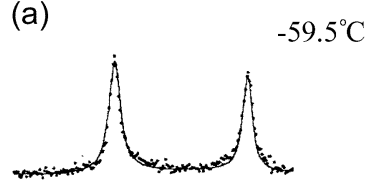

$-39.6^{\circ} \mathrm{C}$

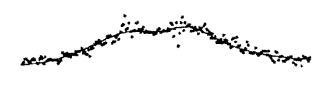

$-19.5^{\circ} \mathrm{C}$

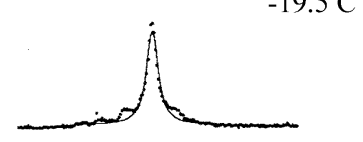

$0.5^{\circ} \mathrm{C}$

$20.6^{\circ} \mathrm{C}$

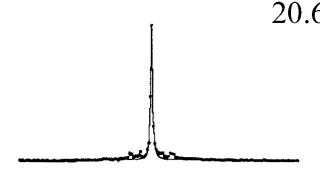

$40.7^{\circ} \mathrm{C}$

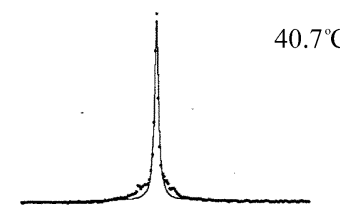

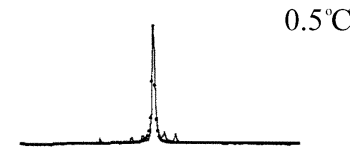

(b)

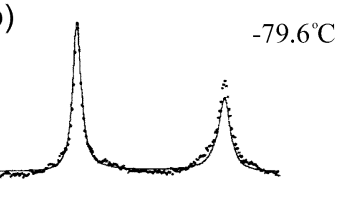

$-59.5^{\circ} \mathrm{C}$

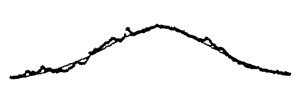

$-39.6^{\circ} \mathrm{C}$

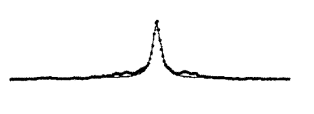

$-19.5^{\circ} \mathrm{C}$

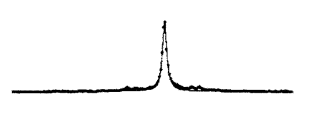

$20.6^{\circ} \mathrm{C}$

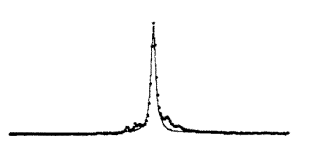

$40.7^{\circ} \mathrm{C}$

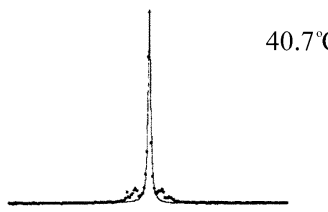

Figure 6. Change of line shape of phenyl protons in (a) $\mathrm{CDCl}_{3}$ and (b) acelone solution (- experimental. - calculated).

3). Of the two phenyl ring proton peaks the one at upper field looks slightly more broadened than the other, indicating that the former protons are located at a closer distance to $\mathrm{Cs}$ ion than the latter. This observation bolsters that our proposed model is quite reasonable. The fact that the cesium NMR spectrum shows only a somewhat broadened single peak for the complexed cesium also supports that the two forms involved in chemical exchange are indeed equivalent. (rigure 7).

In the meantime the cesium spectrum shows that chemical exchange can also take place between bound (or complexed) cesium and free(or solvated) one (rigure 7). This exchange is considered to take place via an exchange mechanism shown in Scheme 3. Another exchange process shown in Scheme 4 may also be considered: however, this is considered to play only a minor role since the concentration of free calixarene would be very low in the presence of excess cesium concentration as thevalues indicate. In order to enhance the accuracy of lineshape fittings we had to increase the intensity of the free (or solvated) $\mathrm{Cs}^{+}$peak by adding $40.7^{\circ} \mathrm{C}$
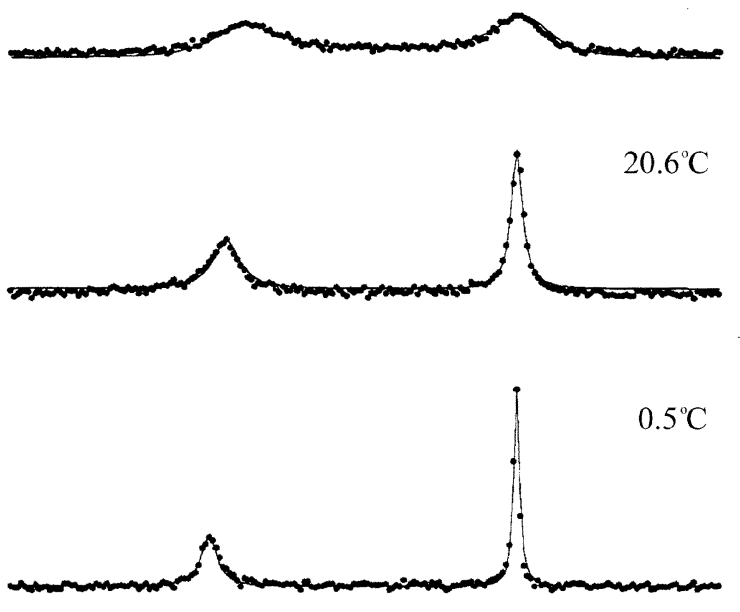

$-19.5^{\circ} \mathrm{C}$

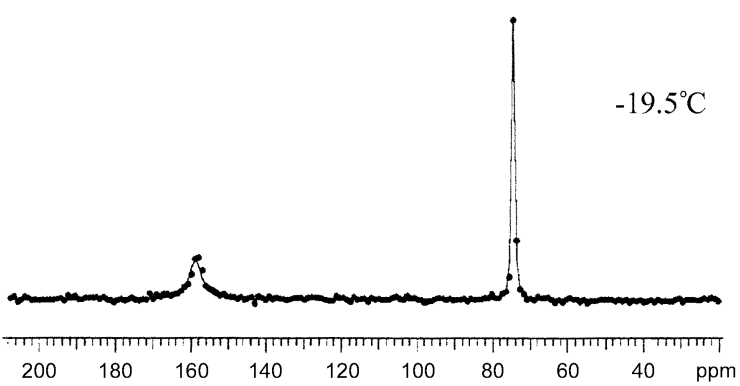

Figure 7. Change of line shape of cesium in acetone solution (experimsntal. - ealculated).

excess amount of cesium picrate since for the hostiguest ratio of $1: 1$ this peak was not strong enough for precise numerical analysis. In our experiment in an acetone solution we added an excess amount of the guest. This certainly enhanced the weak intensity of the solvated $\mathrm{Cs}^{-}$peak to enable better numerical lineshape fitting for acetone solution; however, this strategy has failed to improve the situation in $\mathrm{CDCl}_{3}$, where addition of the salt beyond the ratio of $1: 1$ caused the precipitation of the added cesium picrate, making the precise measurement of exchange rate of $\mathrm{Cs}$ in $\mathrm{CDCl}_{3}$ solution impractical.

For actual lineshape fittings we have treated our system as if it undergoes two separate independent two-site exchange processes, rather than undergoing a simultaneous three-site exchange process, because these two processes were found to have imuch different exchange rate.

The exchange process in Scheme 2 could directly be dealt with for both $\mathrm{CDCl}_{3}$ and acetone- $d$, solution on the basis of two-site exchange theory described in the previous section. However, the lineshape fitting for $\mathrm{Cs}$ exchange according to Scheme 3 was applied only to the acetone- $d$ o solution data

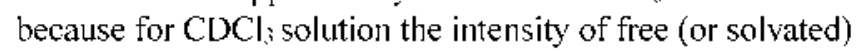
$C s$ ions could not be made strong enough for adequate fitting. The results of the lineshape fitting are graphically presented in rigures 6 and 7 , and the dynamical parameters thereby deduced are also presented in lable 2. Plots of $\ln k_{1}$. $\ln k_{2}$ and $\ln k_{2}$ against inverse temperature yielded the straight lines, from which we could estimate the apparent 

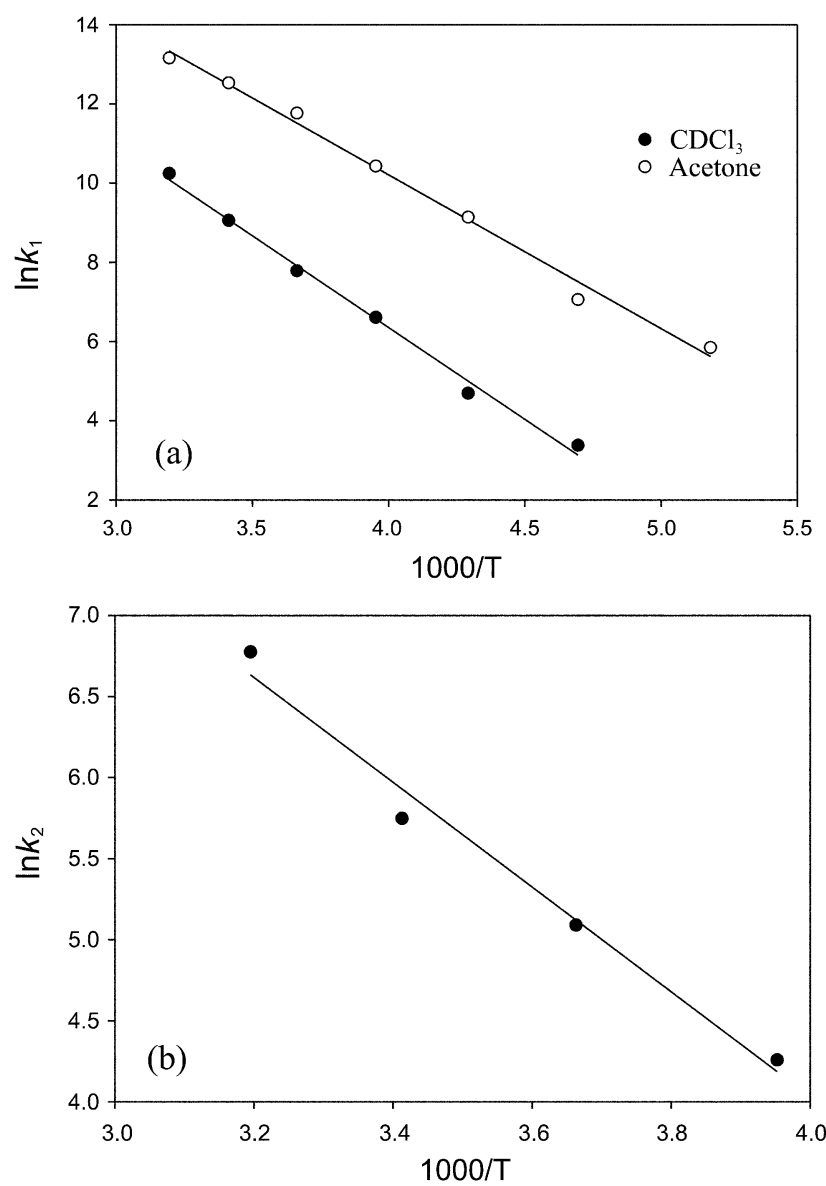

Figure 8. (a) The Arrhenius type plot for phenyl proton data in $C I \mathrm{Cl}_{3}$ and acetone-drs solution; (b) The Arrhenjus type plot for cesium spectral data in acetone solution.

activation energies for the process represented by Scheme 2 and 3 , respectively (Figure 8).

As we see from these results, the rate of the process shown in Scheme 2 is much faster than that of Scheme 3 in acetone solution, indicating that our treatment of these two processes as nearly independent is valid. It goes without saying that the same will also hold for the case of $\mathrm{CDCl}_{3}$ as well. One thing

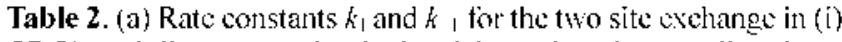
$C D C l_{3}$ and (ii) acelone- $d_{0}$ calculated from phenyl proton line shape in unit of sec ' (b) Sile exchange rate constanls $k_{2}$ and $k_{-2}$ lor the two site exchange in acetone- $d_{6}$ calculated from cesium line shape in unit of $\mathrm{sec}^{-1}$

(a)

\begin{tabular}{lrrrrrrr}
\hline & $-79.5^{\circ} \mathrm{C}$ & $-59.5^{\circ \prime} \mathrm{C}$ & $-39.6^{\circ} \mathrm{C}$ & $-19.5^{\circ} \mathrm{C}$ & $0.5^{\circ} \mathrm{C}$ & $20.6^{\circ} \mathrm{C}$ & $40.7^{\prime \prime} \mathrm{C}$ \\
\hline (i) & $*$ & 30 & 110 & 746 & 2417 & 8625 & 28185 \\
(ii) & 348 & 1169 & 9365 & 33906 & 129145 & 277914 & 520710 \\
\hline
\end{tabular}

(b)

\begin{tabular}{ccccc}
\hline & $-19.5^{\circ} \mathrm{C}$ & $0.5^{\circ \mathrm{C}} \mathrm{C}$ & $20.6^{\circ} \mathrm{C}$ & $40.7^{\circ} \mathrm{C}$ \\
\hline$k_{2}$ & 72 & 168 & 320 & 1449 \\
$k_{-2}$ & 122 & 262 & 481 & 1460 \\
\hline
\end{tabular}

Table 3. (a) Activation paramcters for complexation in $\mathrm{CDCI}_{3}$ and acetone- $d_{0}$ calculated from Fyring equation using $k_{1}$. (b) Aclivation parameters for complexation in acelone- $d_{0}$ calculated from Eyring equation for $k_{2}(\mathrm{I})$ and $k_{-2}(\mathrm{II})$

(a)

\begin{tabular}{|c|c|c|}
\hline Aclivalion Paramelers & $\mathrm{CDCl}_{3}$ & Acetone-ds \\
\hline $\mathrm{E}_{\mathrm{a}}(\mathrm{k} \cdot \mathrm{J} / \mathrm{mol})$ & 38.5 & 32.3 \\
\hline$\Delta \mathrm{H}^{\dot{*}}(\mathrm{k} . \mathrm{I} / \mathrm{mol})$ & 36.4 & 30.2 \\
\hline$\Delta \mathrm{S}^{i}(\mathrm{~J} / \mathrm{mol} \cdot \mathrm{K})$ & -45.2 & -37.7 \\
\hline$\Delta G^{*}=(\mathrm{k} / \mathrm{T} / \mathrm{mol})$ & 49.9 & 41.4 \\
\hline
\end{tabular}

(b)

\begin{tabular}{|c|c|c|}
\hline Aclivalion Parameters & I & 11 \\
\hline$\overline{\mathrm{E}_{\mathrm{a}}(\mathrm{k} . \mathrm{I} / \mathrm{mol})}$ & 31.4 & 26.3 \\
\hline$\Delta \mathrm{H}^{*}(\mathrm{k} \cdot \mathrm{J} / \mathrm{mol})$ & 29.0 & 23.9 \\
\hline$\Delta \mathrm{S}^{*}(\mathrm{~J} / \mathrm{mol} \cdot \mathrm{K})$ & -94.5 & -109.8 \\
\hline 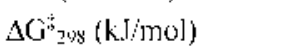 & 57.2 & 56.6 \\
\hline
\end{tabular}

we have to note here is that $k_{1}$, the site exchange rate constant for Scheme 2, a first-order reaction, may be regarded as the reaction rate constant itself, but this is not the case for $k_{2}$ and $k_{2}$, the site exchange rates for the process shown in Scheme 3 , because the exchange process expressed by Scheme 3 is at least a second-order reaction and depends on the concentration of $\mathrm{Cs}^{+}$and the host present at equilibrium. If the process in Scheme 3 is a truly bimolecular elementary process, its reaction rate constants $k_{2}^{\prime}$ and $k_{-2}$ ' would be related to the site exchange rates $k_{2}$ and $k_{2}$, respectively, as follows:

$$
k_{2}=k_{2}^{\prime}\left[\mathrm{Cs}^{-}\right] \text {and } k_{2}=k_{-2}{ }^{\prime} \text { [Complex] }
$$

where $\left[\mathrm{Cs}^{+}\right]$and [Complex] are, respectively, the concentrations of free (or solvated) cesium ion and the $\mathrm{Cs}$-calix complex present in the solution.

Since the forward and the reverse reaction rate constants $k_{2}^{\prime}$ and $k_{-2}{ }^{\prime}$ are equal in magnitude, we have

$$
\frac{k_{2}}{k_{2}}-\frac{\text { [Complex }]}{\left[\mathrm{Cs}^{-}\right]}
$$

As temperature rises, the complex will dissociate more readily, increasing $\left[\mathrm{Cs}^{-}\right]$while decreasing [Complex] and the ratio expressed by Eq. (11) will decrease. This prediction was deduced in the approximation that Scheme 3 is a dominant process for the site exchange for $\mathrm{Cs}^{+}$ion but correctly explains the trend shown by data in Table 2(b) and by figure 7 , at least qualitatively. This makes us well convinced that $\mathrm{CDC} / \mathrm{s}$ solution would show a similar trend. although we were not successful in measuring precise data for lineshape change in the latter solution.

Acknowledgment. The authors appreciate the financial support for this research from the BK21 project of Ministry of Education, Republic of Korea. 


\section{References}

1. (a) Gutsche. C. D. Calixammes: Roval Society of Chemistry: Cambridge, 1989. (b) Vicense, J: Bölmer, V. Calixarenes. A Versatite Closs of Afacroctchic Compounds: Kluwer: Dordrecht. 1990.

2. Valeur. B.: Leray I. Goord. Chem. Res: 1991. 205.3.

3. Casnati. A.: Fischer. C.: Guardigli. M.: Isernia. A.: Manet. I.: Sabbatini. N.: Ungaro. R. J. Chem. Soc. Perhin Trams. 21996. 395.

4. Ludwig. R. Fresentus, J Anat Chemt. 2000. 367, 103.

5. Shinkai. S. Tetrohedron $1993,49,8933$.

6. Marsella. M. J.: Newland. R. J.: Caroll. P. J.: Swager. T. M. J. Am. Chem. Soc. 1995. 117.9842

7. Consoli. G. M. L.: Cunsolo. F.: Geraci. C.: Gavuzzo. En.: Neri. P. Tetrahedron Letters 2002, 13.1209.

8. Kang. S. O.: Nam. K. C. Bull. Korean Chem. Soc. 2002. 23. 640 .

9. Harrowfield. J. M.: Ogden. M. I.: Richmond. W. R.: White. A. H.
J. Chem. Soc. Chem Conmun. 1991. 115.

10. Yamada. A.: Murase. T.: Kikukawa. K.: Arimura. T.: Shinkai. S. $J$. Chent Soc. Perkin Trans 2 1991, 77

11. Beasley. T. M.; Jennings. D. Ention. Sci. Technol 1984. 18 207.

12. Alberts. J. T.: Wahlgren. M. A. Eniron. Sci. Technol 1981. 15.94.

13. Talanova. G. G.: Elkarim. N. S. A.: Talanov. V. S.: Bartsch. R. A. And. Chem. 1999.71.3106

14. Lamare. V; Dozol, J. F.: Fuangswasdi, S.: Arnaud-Neu. F.; Thuery, P.: Nierlich. M: Asfari, Z.: Vicens. J. J. Chent. Soc., Perkin Trans. 21999,271

15. Creaven. B. S.: Deasy. M.: Gallagher. T. F.: MeGinley. T.: Murray. B. A. Tetrahedron 2001. 57.8883 .

16. Brevard. C.: Granger. P. Handbook of High Regolution H Hultinuclear $M R$ : John Wiley \& Sons: New York. 1981

17. Sandström. J. Ehmantic MIR Spectroscopv; Acedemic Press: London. 1981

18. de Boer. J. A. A.: Reinhoudt. D. N. J. Am. Chem. Soc. 1985. 107. 5347. 